\title{
Development and validation of the Parents' Perceived Self-Efficacy to Manage Children's Internet Use Scale for parents of adolescents with attention-deficit/hyperactivity disorder
}

\author{
YI-PING HSIEH ${ }^{1}$, WEN-JIUN CHOU ${ }^{2}$, PENG-WEI WANG ${ }^{3,4} *$ and CHENG-FANG YEN YEN $^{3,4}$ \\ ${ }^{1}$ Department of Social Work, College of Nursing and Professional Disciplines, University of North Dakota, Grand Forks, ND, USA \\ ${ }^{2}$ Department of Child and Adolescent Psychiatry, Chang Gung Memorial Hospital, Kaohsiung Medical Center and College of Medicine, \\ Chang Gung University, Kaohsiung, Taiwan \\ ${ }^{3}$ Department of Psychiatry, School of Medicine, and Graduate Institute of Medicine, College of Medicine, Kaohsiung Medical University, \\ Kaohsiung, Taiwan \\ ${ }^{4}$ Department of Psychiatry, Kaohsiung Medical University Hospital, Kaohsiung, Taiwan
}

(Received: February 14, 2017; revised manuscript received: July 29, 2017; second revised manuscript received: August 31, 2017; accepted: October 1, 2017)

\begin{abstract}
Background and aims: This study developed and validated the Parents' Perceived Self-Efficacy to Manage Children's Internet Use Scale (PSMIS) in the parents of children with attention-deficit/hyperactivity disorder (ADHD). Methods: In total, 231 parents of children with ADHD were invited to complete the PSMIS, followed by the Chen Internet Addiction Scale and the short version of Swanson, Nolan, and Pelham, Version IV Scale - Chinese version for analyzing Internet addiction severity and ADHD symptoms, respectively. Results: The results of exploratory and confirmatory factor analyses confirmed the four-factor structure of the 18-item PSMIS. The significant difference in the levels of parents' perceived self-efficacy between the parents of children with and without Internet addiction supported the criterion-related validity of the PSMIS. The internal consistency and 1-month test-retest reliability were acceptable. Conclusion: The results indicate that the PSMIS has acceptable validity and reliability and can be used for measuring parents' perceived self-efficacy to manage children's Internet use among parents of children with ADHD.
\end{abstract}

Keywords: attention-deficit/hyperactivity disorder, Internet, psychometric, self-efficacy

\section{INTRODUCTION}

The Internet has become a major part of modern daily life. People can use the Internet to conveniently perform many activities, such as communication, recreation, academic activities, daily routine work management, and information search. However, Internet use can become excessive and uncontrolled. Childhood and adolescence are the developmental stages in which young individuals are eager to develop self-identity and social interaction with others as well as to get immediate pleasure and achievement (Gemelli, 1996). The Internet provides children and adolescents with the convenient gateways to accomplish the desired purpose. However, the developing brain of children and adolescents may be insufficient to behaviorally control the impulse and temptation of pursuing pleasure (Steinbeis, Haushofer, Fehr, \& Singer, 2016). Thus, Internet addiction has become a major health issue for children and adolescents. A study on children in grades 3, 5, and 8 in Taiwan reported that the prevalence of Internet addiction was $11.4 \%$ (Chen, Chen, \& Gau, 2015). A prospective study on children in grades 7 and 8 in Taiwan revealed that the 1-year incidence rate for Internet addiction was 7.5\% (Ko, Yen, Yen, Lin, \& Yang, 2007). Internet addiction increases the risks of mental health problems and functional impairment
(Gundogar, Bakim, Ozer, \& Karamustafalioglu, 2012). Therefore, Internet addiction is prevalent among children and adolescents and warrants prevention and intervention.

Several clinical trials of psychological treatments for Internet addiction have been published in recent years, including cognitive behavior therapy, motivational interviewing, reality training, and a combination of psychological and/or counseling therapies within a self-devised treatment program (King, Delfabbro, Griffiths, \& Gradisar, 2011). Several prevention programs against Internet addiction have also been proposed. The B.E.S.T. Teen Program aimed at promoting behavioral, emotional, social, and thinking competencies in primary school students to reduce the risk of Internet addiction (Shek, Yu, Leung, Wu, \& Law, 2016). The Project P.A.T.H.S. aims at reducing adolescents'

\footnotetext{
* Corresponding authors: Cheng-Fang Yen, MD, PhD; Department of Psychiatry, Kaohsiung Medical University Hospital, No. 100, Tzyou 1st Rd., Kaohsiung 807, Taiwan; Phone: +886 73121101 ext. 6816; Fax: +886 7313 4761; E-mail: chfaye@cc.kmu.edu.tw; Peng-Wei Wang, MD, PhD; Department of Psychiatry, Kaohsiung Medical University Hospital, No. 100, Tzyou 1st Rd., Kaohsiung 807, Taiwan; Phone: +88673121101 ext. 6822; Fax: +886 7313 4761; E-mail: wistar.huang@gmail.com
} 
Internet addiction primarily by improving their psychosocial competencies (Shek, Ma, \& Sun, 2011). However, these treatment and prevention programs focused on the children and adolescents in the form of individual or group intervention. Social context is an important influence on adolescent health (Rutter, 1993). Previous studies have found that high family conflict and low family function increased the risk of Internet addiction in adolescents (Yen, Yen, Chen, Chen, \& Ko, 2007). Meanwhile, Internet activities usually have no predefined stopping points (Van den Bulck, 2000). Without effective supervision and discipline in the family, the nature of the Internet activities described here will attract children's and adolescents' excessive engagement and increase the risk of development of Internet addiction (Yen, Ko, Yen, Chang, $\&$ Cheng, 2009). Moreover, since Internet addiction often occurs in the family context, which results in serious conflicts between the youths and their parents, family-based counseling is considered important (Shek, Tang, \& Lo, 2009). Family-based counseling includes reframing the symptoms of Internet addiction, dealing with unbalanced family power structure, resolution of conflicts and facilitation of congruent communication, and identification and discussion of the stages of change (Hanna \& Brown, 1995). However, whether the parents of the youths have sufficient self-efficacy to practice the skills learned from these prevention and intervention programs is important to successfully execute the management plan for the children's and adolescents' Internet use.

Both cross-sectional (Cao, Su, Liu, \& Gao, 2007; Yen, Ko, Yen, Wu, \& Yang, 2007; Yoo et al., 2004) and longitudinal (Chen et al., 2015; Ko, Yen, Chen, Yeh, \& Yen, 2009) community studies have found significant associations between Internet addiction and attention-deficit/ hyperactivity disorder (ADHD) symptoms in children and adolescents. ADHD is the most common psychiatric disorder among adolescents with Internet addiction who have been referred for psychiatric treatment (Bozkurt, Coskun, Ayaydin, Adak, \& Zoroglu, 2013). Several biopsychosocial mechanisms, such as the tendencies of being easily bored and having an aversion to delayed reward, impaired inhibition, motivation deficit, and low achievement in real lives, have been proposed to explain the significant association between Internet addiction and ADHD (Ko, Yen, Yen, Chen, \& Chen, 2012). Moreover, compared with those without ADHD, children with ADHD had increased parent-child conflict (Edwards, Barkley, Laneri, Fletcher, \& Metevia, 2001). The parental management of the Internet use of children and adolescents with ADHD may increase the parent-adolescent conflict. However, no study has examined the levels of and correlation between parents' perceived self-efficacy and their management of the Internet use of children and adolescents with ADHD. Thus, parents must have sufficient parents' self-efficacy to communicate with the adolescents and execute the management plan for the children's and adolescents' Internet use.

Surveying parents' self-efficacy is essential when developing plans for managing children's and adolescents' Internet use with the parents of children and adolescents with ADHD. A reliable instrument is essential for studying the parents' self-efficacy to manage children's Internet use. Therefore, this study developed and validated the Parents'
Perceived Self-Efficacy to Manage Children's Internet Use Scale (PSMIS) among parents of children with ADHD.

\section{METHODS}

\section{Participants and procedure}

Parents of children aged 11-18 years who had been diagnosed as having ADHD, according to the diagnostic criteria in the Diagnostic and Statistical Manual of Mental Disorders, Fifth Edition (DSM-5) (American Psychiatric Association, 2013), were consecutively recruited into this study between August 2014 and July 2015 from the child and adolescent psychiatric outpatient clinics of two medical centers in Kaohsiung, Taiwan. Two child psychiatrists conducted diagnostic interviews with the parents to make the diagnosis of ADHD according to the DSM-5 diagnostic criteria. Multiple data sources, including clinical observation of the children's behavior and the parent rating of ADHD symptoms on the short version of Swanson, Nolan, and Pelham, Version IV Scale - Chinese version (SNAPIV) (Gau et al., 2008; Swanson et al., 2001), were also used to support the diagnosis. Parents of children with intellectual disability, schizophrenia, bipolar disorder, autistic disorder with difficulties in communication, or any cognitive deficits that resulted in significant behavioral and emotional difficulties were excluded.

In total, 237 parents of children with ADHD were invited into this study; of them, 231 (97.5\%) agreed to participate. The participants could ask the research assistants if they had problems in completing the questionnaires. Thirty participants were completed the PSMIS again 1 month later to confirm the test-retest reliability. Informed consent was obtained from all the participants prior to the assessment. The Institutional Review Boards of Kaohsiung Medical University and Chang Gung Memorial Hospital, Kaohsiung Medical Center approved the study (KMUHIRB-20130131).

\section{Measures}

PSMIS. We developed the PSMIS on the basis of the safe Internet use behaviors proposed by Siomos et al. (2012) and the knowledge and skills parents required to successfully manage their children's Internet use proposed by Chou (2007). Siomos et al. (2012) proposed the questionnaire regarding Internet security measures that the parents should take in order to make the web browsing experience secure for their children. The questionnaire queried on the use of parental control and content filtering programs, creating a fair Internet use "contract," actively participating in the initial introduction to the Internet and creating a list with appropriate web pages and search engines, periodically checking bookmarks and browsing history, placing the personal computer in plain view while teaching the children to avoid uploading personal data online and meeting inperson online acquaintances. Chou (2007) proposed the knowledge and skills that parents required to successfully manage their children's Internet use and overuse, online peer interaction, Internet-related illegality and pornography, and cyberbullying. The original version of the PSMIS 
contained 28 items for measuring the level of parents' perceived self-efficacy to successfully manage children's Internet use in the recent 1 month. The 28 items contained all the behaviors, knowledge, and skills parents required to successfully manage children's Internet use mentioned above. Each item was rated on a 7-point Likert scale - 0 (no efficacy at all) to 6 (extremely strong efficacy). We invited five experts on child and adolescent psychiatry to examine the items contained in the original version of the PSMIS and to rate the adequacy of the items on a 4-point Likert scale - 0 (not adequate at all) to 3 (extremely adequate). On the basis of the comments from these five experts, we revised the PSMIS and sent the revised version to these five experts again for rating the level of adequacy. The 24 items with the adequacy rating of 3 (extremely adequate) were finally retained on the PSMIS; this scale was used for measuring parents' perceived self-efficacy to manage children's Internet use.

Chen Internet Addiction Scale (CIAS). We used the parent-reported Chen Internet Addiction Scale to assess children's severity of Internet addiction in the recent 1 month. The CIAS contains 26 items on a 4-point Likert scale with scaled score ranging from 26 to 104 (Chen, Weng, Su, Wu, \& Yang, 2003). The CIAS contains five subscales, including compulsive symptoms, withdrawal symptoms, tolerance symptoms, interpersonal and health problems, and time management problems, with the internal reliability (Cronbach's $\alpha$ ) .77, .81, .77, .80, and .74, respectively. Higher total subscale score indicates severer Internet addiction on each subscale. Ko et al. (2005) demonstrated that the 63-64 cutoff point of the CIAS is the optimal diagnostic cutoff point for Internet addiction in children. Participants with total CIAS scores of 64 or higher were accordingly identified as having Internet addiction.

$A D H D$ and oppositional symptoms. The short version of SNAP-IV - Chinese version was used for assessing the severity of ADHD and oppositional symptoms in the recent 1 month. The aforementioned scale is a 26-item rating instrument including the core DSM-IV-derived ADHD subscales of inattention, hyperactivity/impulsivity, and oppositional symptoms of oppositional defiant disorder (Gau et al., 2008; Swanson et al., 2001). Each item is rated on a 4-point Likert scale - 0 (not at all) to 3 (very much). The Cronbach's $\alpha$ of inattention, hyperactivity/impulsivity, and oppositional subscales in this study was $.91, .90$, and .93 , respectively.

\section{Statistical analysis}

Data analysis was performed using SPSS (version 24.0) (IBM Corporation, 2016) and LISREL (version 9.1) statistical software (Jöreskog \& Sörbom, 2006) statistical software. The factor structure and construct validity of the PSMIS were studied through exploratory and confirmatory factor analyses. The criterion-related validity of the PSMIS was examined by comparing the differences in the PSMIS results between the parents of the children with and without Internet addiction using $t$-test. The correlations of parents' perceived self-efficacy on the PSMIS subscales with children's Internet addiction on the CIAS subscales and ADHD and oppositional symptoms on the SNAP-IV - Chinese version were examined using Pearson's correlation. The method of internal consistency (Cronbach's $\alpha$ ) was employed for analyzing reliability. The 1-month test-retest reliability was examined using Pearson's correlation.

\section{Ethics}

The study procedures were carried out in accordance with the Declaration of Helsinki. The Institutional Review Boards of Kaohsiung Medical University and Chang Gung Memorial Hospital, Kaohsiung Medical Center approved the study. All participants were informed about the study and provided informed consent.

\section{RESULTS}

Parents' and children's sociodemographic characteristics and children's ADHD symptoms are listed in Table 1.

\section{Construct validity}

Exploratory factor analysis. An exploratory factor analysis (EFA) was conducted on a sample of 231 parents having children with ADHD. The Kaiser-Meyer-Olkin coefficient of sampling adequacy was within the excellent range at .94 . The Bartlett's Test of Sphericity, which examines whether a matrix is different from the identity matrix, provided significant results, indicating that the matrix did not resemble the identity matrix; this further supported the presence of

Table 1. Parents' and children's sociodemographic characteristics and children's ADHD symptoms $(N=231)$

\begin{tabular}{|c|c|c|}
\hline & $n(\%)$ & $\begin{array}{c}\text { Mean } \\
(S D)\end{array}$ \\
\hline \multicolumn{3}{|l|}{ Gender of parents } \\
\hline Female & $192(83.1)$ & \\
\hline Male & $39(16.9)$ & \\
\hline \multicolumn{3}{|l|}{ Gender of children } \\
\hline Female & $32(13.9)$ & \\
\hline Male & $199(86.1)$ & \\
\hline Age of parents (years) & & $43.8(6.1)$ \\
\hline Age of children (years) & & $13.7(1.8)$ \\
\hline \multicolumn{3}{|l|}{ Marriage status of parents } \\
\hline Intact & $190(82.3)$ & \\
\hline Not intact & $41(17.7)$ & \\
\hline $\begin{array}{l}\text { Education duration of parents } \\
\text { (years) }\end{array}$ & & $13.8(2.8)$ \\
\hline \multicolumn{3}{|l|}{ SNAP-IV symptoms of children } \\
\hline Inattention & & $12.7(6.1)$ \\
\hline Hyperactivity/impulsivity & & $8.8(6.0)$ \\
\hline Oppositional defiant & & $9.9(5.8)$ \\
\hline \multicolumn{3}{|l|}{ Internet addiction on the CIAS } \\
\hline Compulsive symptoms & & $10.6(3.8)$ \\
\hline Withdrawal symptoms & & $11.6(3.8)$ \\
\hline Tolerance symptoms & & $9.4(3.0)$ \\
\hline Interpersonal and health problems & & $14.1(4.8)$ \\
\hline Time management problems & & $9.5(3.3)$ \\
\hline
\end{tabular}

Note. ADHD: attention-deficit/hyperactivity disorder; $S D$ : standard deviation; CIAS: Chen Internet Addiction Scale; SNAP-IV: short version of the Swanson, Nolan, and Pelham Version IV Scale Chinese version. 
factors within the data. We identified factor eigenvalues that were greater than 1 to determine the number of factors. Principal axis factor analysis was conducted and the Promax rotation method, which rotates the factor structure on the basis of the assumption that factors are correlated, was used to determine the factor solutions. The initial result indicated a four-factor solution for all 24 items. After eliminating four items with lower loadings $(<0.60)$, the remaining 20 items were applied to run the factor analysis again. Two items were then eliminated one because of low correlation and the other because of improvement in $\alpha$ value. Thereafter, the final 18 items were applied to run the factor analysis. The results indicated a four-factor solution with eigenvalues of $9.45,1.57,1.18$, and 1.06 for each factor. The items and factors in the scope of the scale explained $73.65 \%$ of the total variance. The means, standard deviations $(S D)$, and factor loadings for subscales are presented in Table 2. The four-factor solution emerged from the results of the EFA, which fit with the theoretical factors used to devise the measurement tool.

The first subscale, "safety management" $(\alpha=.88)$, includes six items with factor loadings of $0.62-0.93$; its items reflect parents' perceived efficacy of management of children's online safety and problem-solving practice on the problems of meeting with online friends, online crime, online overspending, cyberbullying, and Internet addiction. The second factor, "parental reasoning" $(\alpha=.92)$, includes four items with factor loadings of $0.67-0.81$; its items reflect parents' perceived efficacy of active mediation on children's Internet use through positive communication and reasoning. The third factor, "rule-setting practice" $(\alpha=.91)$, includes four items with factor loadings of $0.74-0.86$; its items reflect the parents' perceived efficacy of rule-setting practice on the amount of time and timing of children's Internet use to prevent negative impacts on children's daily-life functioning. The fourth factor, "parental monitoring" $(\alpha=.86)$, includes four items with factor loadings of $0.73-0.87$; its items reflect parents' perceived efficacy of monitoring on what the children do, whom they talk with, and where they go online. The bivariate correlations among PSMIS items are shown in Table 3.

Confirmatory factor analysis. On the basis of the results of the EFA, a confirmatory factor analysis was employed using maximum likelihood estimation. A good model fit is indicated by a comparative fit index (CFI) of $>0.90$ (Kline, 2005), root mean square error of approximation (RMSEA) of $<0.08$, standardized root mean square residual (SRMR) of $<0.10$, and Tucker-Lewis Index (TLI) of $>0.95$ (Brown $\&$ Cudeck, 1993; Kline, 2005). The current model showed an acceptable fit to the data $\left(\chi^{2}=343.51, d f=129 ; p<.001\right.$; $\mathrm{CFI}=0.98 ; \mathrm{RMSEA}=0.08 ; \mathrm{SRMR}=0.06 ; \mathrm{TLI}=0.97)$.

\section{Criterion validity}

The CIAS was used to determine the criterion-related validity of the PSMIS. The independent sample $t$-test results

Table 2. Means, standard deviations, Cronbach's $\alpha$, and factor loadings for the PSMIS items

\begin{tabular}{|c|c|c|c|c|c|c|}
\hline Factors and items & Mean & $S D$ & $\mathrm{~F} 1$ & F2 & F3 & $\mathrm{F} 4$ \\
\hline \multicolumn{7}{|l|}{ Safety management $(\alpha=.88)$} \\
\hline 1. I intervene effectively when my child asks to go out with online friends & 4.65 & 1.44 & 0.81 & & & \\
\hline 2. I manage my child's online expenditure & 4.89 & 1.24 & 0.76 & & & \\
\hline 3. I know the signs of Internet overuse & 4.57 & 1.18 & 0.76 & & & \\
\hline $\begin{array}{l}\text { 4. I observe my child to see if he/she is involved in cyberbullying or victimization and } \\
\text { intervene effectively }\end{array}$ & 4.45 & 1.44 & 0.71 & & & \\
\hline 5. I manage my child's Internet use outside the house & 4.69 & 1.46 & 0.68 & & & \\
\hline $\begin{array}{l}\text { 6. I manage my child's activities to prevent him/her from committing online crimes or } \\
\text { breaking laws }\end{array}$ & 4.58 & 1.35 & 0.67 & & & \\
\hline \multicolumn{7}{|l|}{ Parental reasoning $(\alpha=.92)$} \\
\hline 7. I don't distress my child while communicating with him/her about Internet use & 3.87 & 1.47 & & 0.93 & & \\
\hline 8. I don't make the family atmosphere tense when I manage my child's Internet use & 3.90 & 1.46 & & 0.93 & & \\
\hline 9. I don't get angry when I manage my child's Internet use & 3.60 & 1.64 & & 0.90 & & \\
\hline $\begin{array}{l}\text { 10. I communicate with my child effectively and let him/her know the reasons for managing } \\
\text { his/her Internet use }\end{array}$ & 4.34 & 1.31 & & 0.62 & & \\
\hline \multicolumn{7}{|l|}{ Rule-setting practice $(\alpha=.91)$} \\
\hline 11. I manage my child's Internet use to prevent negative effects on his/her daily life & 4.74 & 1.24 & & & 0.86 & \\
\hline 12. I don't allow my child to play on the Internet while doing homework & 4.76 & 1.28 & & & 0.84 & \\
\hline 13. When my child spends excessive time on the Internet, I stop him/her effectively & 4.80 & 1.16 & & & 0.84 & \\
\hline 14. I effectively manage when my child can or cannot use the Internet & 4.28 & 1.44 & & & 0.74 & \\
\hline \multicolumn{7}{|l|}{ Parental monitoring $(\alpha=.86)$} \\
\hline 15. I monitor the websites my child visits & 4.10 & 1.58 & & & & 0.87 \\
\hline 16. I know whom my child talks with and what he/she talks about on the Internet & 3.81 & 1.63 & & & & 0.78 \\
\hline 17. I don't allow my child to surf on certain types of websites & 4.28 & 1.54 & & & & 0.77 \\
\hline 18. I use software or control programs to monitor and manage my child's Internet use & 4.20 & 1.51 & & & & 0.73 \\
\hline Mean & & & 4.64 & 3.99 & 4.69 & 4.10 \\
\hline$S D$ & & & 1.07 & 1.30 & 1.07 & 1.31 \\
\hline
\end{tabular}

Note. PSMIS: Parents' Perceived Self-Efficacy to Manage Children's Internet Use Scale; SD: standard deviation; F1: factor 1 (safety management); F2: factor 2 (parental reasoning); F3: factor 3 (rule-setting practice); F4: factor 4 (parental monitoring). 


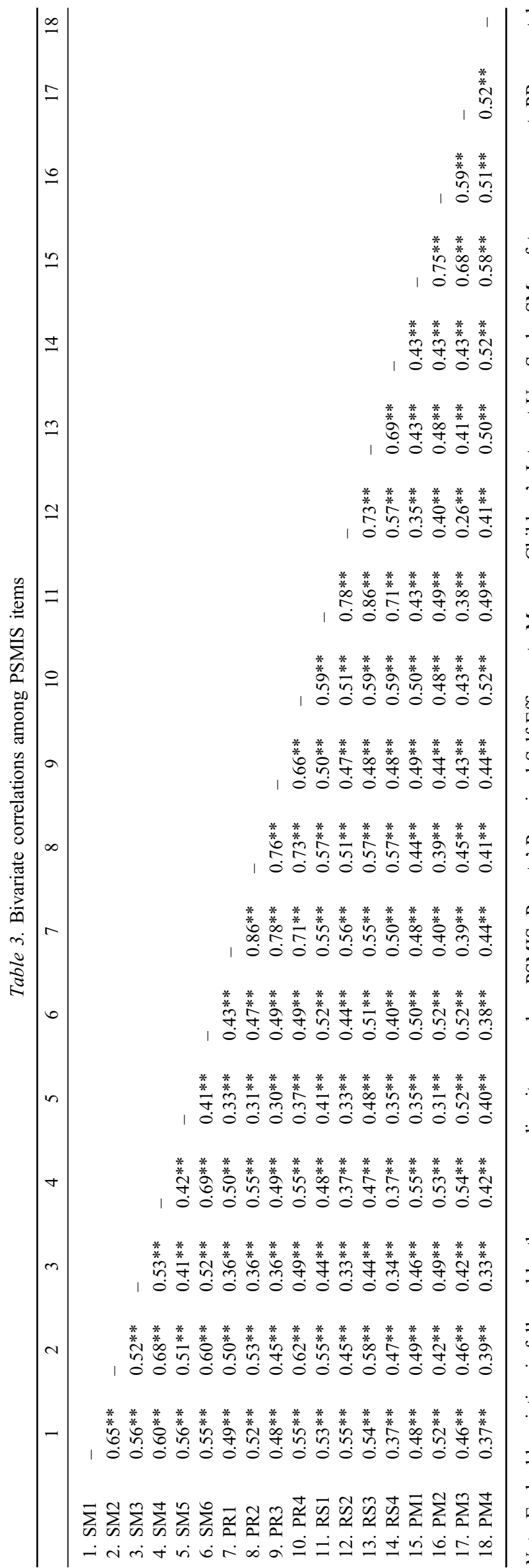

provided strong evidence for known-groups validity, a subtype of criterion-related validity. We compared the differences in the PSMIS results between the parents of children with and without Internet addiction (Table 4). The results indicate that the parents of children with Internet addiction had lower scores on all four subscales on the PSMIS than did those of children without Internet addiction. The correlation coefficients of the PSMIS subscales with the CIAS subscales and ADHD and oppositional symptoms are shown in Table 5. The results of Pearson's correlation indicated that all four subscales on the PSMIS were significantly and negatively correlated with the five subscales on the CIAS $(p<.001)$. The subscales of safety management, parental reasoning, and rule-setting practice were negatively correlated with inattention and oppositional symptoms, whereas only the subscale of parental reasoning was negatively correlated with hyperactivity/impulsivity. The subscale of parental monitoring was not significantly correlated with ADHD and oppositional symptoms.

\section{Reliability}

The internal consistency coefficients, Cronbach's $\alpha$ values, for the safety management, parental reasoning, rule-setting practice, and parental monitoring subscales were $0.88,0.92$, 0.91 , and 0.86 , respectively. The 1-month test-retest reliability of the four subscales of the PSMIS (Pearson's correlation $r$ ) among the 30 parents of children with ADHD was $0.74-0.81(p<.001)$.

\section{DISCUSSION}

In this study, we developed and validated the PSMIS for measuring parents' perceived efficacy to manage Internet use of children with ADHD. The final version of the 18-item PSMIS contains four subscales - safety management, parental reasoning, rule-setting practice, and parental monitoring. Our results indicate that the PSMIS has acceptable validity and reliability for measuring whether parents of children with ADHD have sufficient efficacy of and the

Table 4. Comparison of parents' perceived efficacy to manage children's Internet use between parents of children with and without Internet addiction

\begin{tabular}{lcccc}
\hline & $\begin{array}{c}\text { Have } \\
\text { Internet } \\
\text { addiction } \\
(n=73), \\
\text { mean }(S D)\end{array}$ & $\begin{array}{c}\text { No Internet } \\
\text { addiction } \\
(n=158), \\
\text { mean }(S D)\end{array}$ & $t$ & $p$ \\
\hline $\begin{array}{c}\text { Safety } \\
\text { management }\end{array}$ & $4.20(1.18)$ & $4.84(0.95)$ & -4.37 & $<.001$ \\
$\begin{array}{c}\text { Parental } \\
\text { reasoning }\end{array}$ & $3.14(1.36)$ & $4.29(1.15)$ & -6.66 & $<.001$ \\
$\begin{array}{c}\text { Rule-setting } \\
\text { practice }\end{array}$ & $3.99(1.36)$ & $4.95(0.86)$ & -5.55 & $<.001$ \\
$\begin{array}{c}\text { Parental } \\
\text { monitoring }\end{array}$ & $3.58(1.34)$ & $4.34(1.23)$ & -4.25 & $<.001$ \\
\hline
\end{tabular}

Note. SD: standard deviation. 
Table 5. Correlations between parents' perceived efficacy to manage children's Internet use and children's Internet addiction and ADHD and oppositional symptoms

\begin{tabular}{|c|c|c|c|c|c|c|c|c|}
\hline \multirow{3}{*}{$\begin{array}{l}\text { Parents' } \\
\text { perceived } \\
\text { self-efficacy } \\
\text { to manage }\end{array}$} & \multicolumn{5}{|c|}{ Internet addiction } & \multicolumn{3}{|c|}{ ADHD and oppositional symptoms } \\
\hline & $\begin{array}{l}\text { Compulsive } \\
\text { symptoms }\end{array}$ & $\begin{array}{l}\text { Withdrawal } \\
\text { symptoms }\end{array}$ & $\begin{array}{l}\text { Tolerance } \\
\text { symptoms }\end{array}$ & $\begin{array}{l}\text { Interpersonal and } \\
\text { health problems }\end{array}$ & $\begin{array}{c}\text { Time } \\
\text { management } \\
\text { problems }\end{array}$ & Inattention & $\begin{array}{l}\text { Hyperactivity/ } \\
\text { impulsivity }\end{array}$ & $\begin{array}{l}\text { Oppositional } \\
\text { defiant }\end{array}$ \\
\hline & $r$ & $r$ & $r$ & $r$ & $r$ & $r$ & $r$ & $r$ \\
\hline $\begin{array}{l}\text { Safety } \\
\text { management }\end{array}$ & $-.33 * * *$ & $-.28 * * *$ & $-.33 * * *$ & $-.39 * * *$ & $-.39 * * *$ & $-.15^{*}$ & -.11 & $-.28^{* * *}$ \\
\hline $\begin{array}{l}\text { Parental } \\
\text { reasoning }\end{array}$ & $-.55^{* * *}$ & $-.50^{* * *}$ & $-.50^{* * *}$ & $-.52^{* * *}$ & $-.52 * * *$ & $-.22^{* *}$ & $-.23^{* * *}$ & $-.38^{* * *}$ \\
\hline $\begin{array}{l}\text { Rule-setting } \\
\text { practice }\end{array}$ & $-.53 * * *$ & $-.38 * * *$ & $-.50^{* * *}$ & $-.47 * * *$ & $-.58^{* * *}$ & $-.17^{*}$ & -.08 & $-.31^{* * *}$ \\
\hline $\begin{array}{l}\text { Parental } \\
\text { monitoring }\end{array}$ & $-.42 * * *$ & $-.35 * * *$ & $-.39 * * *$ & $-.39 * * *$ & $-.42 * * *$ & -.11 & -.08 & -.12 \\
\hline
\end{tabular}

Note. ADHD: attention-deficit/hyperactivity disorder.

${ }^{*} p<.05$. ${ }^{* *} p<.01 .{ }^{* * *} p<.001$.

necessary knowledge and skills required for successfully managing their children's Internet use.

We also noted that the levels of parents' perceived efficacy on all four subscales of the PSMIS were significantly lower in the parents of ADHD children with Internet addiction than in those of ADHD children without Internet addiction. Our cross-sectional research design limited the possibility to draw a causal relationship between parents' perceived efficacy to manage children's Internet use and the children's Internet addiction. Children with ADHD have biopsychosocial vulnerabilities for Internet addiction (Ko et al., 2012); thus, the lack of efficient parental management in these cases may increase the risk losing control over the children's Internet use. By contrast, ADHD children with Internet addiction may refuse to comply with parental management of their Internet use and even fight with parents for the right to use Internet; thus, the parents may report low efficacy when managing their children's Internet use. In addition, all four subscales on the PSMIS were significantly and negatively correlated with the five subscales on the CIAS. This result indicates that parents' perceived self-efficacy for managing their children's Internet addiction is one of correlates of Internet addiction in children with ADHD.

We found that the parents' perceived self-efficacy on the four subscales of the PSMIS had various associations with Internet addiction. The difference in the subscale of parental reasoning between parents of children with and without Internet addiction was the most significant $(t=-6.66)$, whereas the differences in the subscales of safety management $(t=-4.37)$ and parental monitoring $(t=-4.25)$ were less significant. The Pearson's correlation coefficients between the subscale of parental reasoning and Internet addiction on the five subscales of Internet addiction were all higher than 0.5 , indicating a large strength of association. However, the Pearson's correlation coefficients between the subscale of safety management and Internet addiction on the five subscales of Internet addiction were all lower than 0.4, indicating a medium strength of association. "Parental reasoning" reflects parents' ability to actively mediate children's Internet use through positive communication and reasoning. Parents who have good efficacy to communicate with children may well manage children's Internet use without evoking parent-child conflict. "Safety management" reflects parents' ability to manage children's online safety and solve the problems children meet online, which may be less associated with the risk of Internet addiction compared with parental reasoning. Moreover, this study found that the four subscales of the PSMIS had various correlations with ADHD and oppositional symptoms. The participants in this study were the parents of children who received pharmacological or psychological treatment for ADHD. Their ADHD and oppositional symptoms may partially subside. Thus, the correlation between parents' perceived self-efficacy on manage children's Internet use and children's ADHD and oppositional symptoms may be influenced.

This study examined the psychometrics of parents of children with ADHD using the PSMIS. Whether this psychometrics is acceptable for analyzing parents of children without ADHD warrants additional studies. The tendency of individuals with ADHD of developing Internet addiction is high and the parental management of children's Internet use is crucial; therefore, the PSMIS can be used as a tool for measuring parents' perceived efficacy to manage the Internet use of children with ADHD. The results of this measurement may become the bases for developing Internet addiction prevention programs for children with ADHD.

Funding sources: This study was supported by the grants (MOST 103-2314-B-182A-013 and 104-2314-B-182A030) from the Ministry of Science and Technology, Taiwan, R.O.C.

Authors' contribution: Y-PH: study concept and design, analysis, and interpretation of data, and statistical analysis; W-JC: study concept and design, obtained funding, and study supervision; P-WW: analysis and interpretation of data and statistical analysis; C-FY: study concept and design, analysis, and interpretation of data, statistical analysis, obtained funding, and study supervision. All authors 
had full access to all data in the study and take responsibility for the integrity of the data and the accuracy of the data analysis. Dr. Y-PH and Dr. W-JC contributed equally to this study.

Conflict of interest: The authors declare no conflict of interest.

\section{REFERENCES}

American Psychiatric Association. (2013). Diagnostic and statistical manual of mental disorders (5th ed.). Washington, DC: American Psychiatric Association.

Bozkurt, H., Coskun, M., Ayaydin, H., Adak, I., \& Zoroglu, S. S. (2013). Prevalence and patterns of psychiatric disorders in referred adolescents with Internet addiction. Psychiatry and Clinical Neurosciences, 67(5), 352-359. doi:10.1111/ pcn. 12065

Brown, M. W., \& Cudeck, R. (1993). Alternative ways of assessing model fit. In K. A. Bollen \& J. S. Long (Eds.), Testing structural equation models (pp. 136-162). Beverly Hills, CA: SAGE Publications.

Cao, F., Su, L., Liu, T., \& Gao, X. (2007). The relationship between impulsivity and Internet addiction in a sample of Chinese adolescents. European Psychiatry, 22(7), 466-471. doi:10.1016/j.eurpsy.2007.05.004

Chen, Y. L., Chen, S. H., \& Gau, S. S. F. (2015). ADHD and autistic traits, family function, parenting style, and social adjustment for Internet addiction among children and adolescents in Taiwan: A longitudinal study. Research in Developmental Disabilities, 39, 20-31. doi:10.1016/j.ridd.2014.12.025.

Chen, S. H., Weng, L. C., Su, Y. J., Wu, H. M., \& Yang, P. F. (2003). Development of Chinese Internet Addiction Scale and its psychometric study. Chinese Journal of Psychology, 45(3), 279-294. doi:10.6129/CJP.2003.4503.05

Chou, C. (2007). Understanding children's Internet world: The general capacity and disposition of parents. Taipei, Taiwan: Ministry of Education.

Edwards, G., Barkley, R. A., Laneri, M., Fletcher, K., \& Metevia, L. (2001). Parent-adolescent conflict in teenagers with ADHD and ODD. Journal of Abnormal Child Psychology, 29(6), 557572. doi:10.1023/A:1012285326937

Gau, S. S. F., Shang, C. Y., Liu, S. K., Lin, C. H., Swanson, J. M., Liu, Y. C., \& Tu, C. L. (2008). Psychometric properties of the Chinese version of the Swanson, Nolan, and Pelham, version IV scale - Parent form. International Journal of Methods in Psychiatric Research, 17(1), 35-44. doi:10.1002/mpr.237

Gemelli, R. (1996). Normal child and adolescent development ( $\mathrm{p}$. 448). Washington, DC: American Psychiatric Press, Inc.

Gundogar, A., Bakim, B., Ozer, O. A., \& Karamustafalioglu, O. (2012). P-32 - The association between internet addiction, depression and ADHD among high school students. European Psychiatry, 27, 1. doi:10.1016/S0924-9338(12)74199-8

Hanna, S. M., \& Brown, J. H. (1995). The practice of family therapy: Key elements across models. Pacific Grove, CA: Brooks/Cole.

IBM Corporation. (2016). IBM SPSS statistics for Windows (version 24.0.) [Computer software]. Armonk, NY: IBM Corporation.
Jöreskog, K. G., \& Sörbom, D. (2012). LISREL for Windows (version 9.10) [Computer software]. Skokie, IL: Scientific Software International.

King, D. L., Delfabbro, P. H., Griffiths, M. D., \& Gradisar, M. (2011). Assessing clinical trials of Internet addiction treatment: A systematic review and CONSORT evaluation. Clinical Psychology Review, 31(7), 1110-1116. doi:10.1016/j. cpr.2011.06.009

Kline, R. B. (2005). Principles and practice of structural equation modeling (2nd ed.). New York, NY: Guilford Press.

Ko, C. H., Yen, J. Y., Chen, C. S., Yeh, Y. C., \& Yen, C. F. (2009). Predictive values of psychiatric symptoms for Internet addiction in adolescents: A 2-year prospective study. Archives of Pediatrics \& Adolescent Medicine, 163(10), 937-943. doi:10.1001/archpediatrics.2009.159

Ko, C. H., Yen, J. Y., Yen, C. F., Chen, C. S., \& Chen, C. C. (2012). The association between Internet addiction and psychiatric disorder: A review of the literature. European Psychiatry, 27(1), 1-8. doi:10.1016/j.eurpsy.2010.04.011

Ko, C. H., Yen, J. Y., Yen, C. F., Lin, H. C., \& Yang, M. J. (2007). Factors predictive for incidence and remission of Internet addiction in young adolescents: A prospective study. CyberPsychology \& Behavior, 10(4), 545-551. doi:10.1089/ cpb.2007.9992

Ko, C. H., Yen, C. F., Yen, C. N., Yen, J. Y., Chen, C. C., \& Chen, S. H. (2005). Screening for Internet addiction: An empirical study on cut-off points for the Chen Internet Addiction Scale. The Kaohsiung Journal of Medical Sciences, 21(12), 545-551. doi:10.1016/S1607-551X(09)70206-2

Rutter, M. (1993). Resilience: Some conceptual considerations. Journal of Adolescent Health, 14(8), 626-631. doi:10.1016/ 1054-139X(93)90196-V

Shek, D. T., Ma, H. K., \& Sun, R. C. (2011). Development of a new curriculum in a positive youth development program: The project P.A.T.H.S. in Hong Kong. Scientific World Journal, 11, 2207-2218. doi:10.1100/2011/289589

Shek, D. T. L., Tang, V. M. Y., \& Lo, C. Y. (2009). Evaluation of an Internet addiction treatment program for Chinese adolescents in Hong Kong. Adolescence, 44(174), 359-373.

Shek, D. T. L., Yu, L., Leung, H., Wu, F. K. Y., \& Law, M. Y. M. (2016). Development, implementation, and evaluation of a multi-addiction prevention program for primary school students in Hong Kong: The B.E.S.T. Teen Program. Asian Journal of Gambling Issues and Public Health, 6(1), 5. doi:10.1186/s40405-016-0014-Z

Siomos, K., Floros, G., Fisoun, V., Evaggelia, D., Farkonas, N., Sergentani, E., Lamprou, M., \& Geroukalis, D. (2012). Evolution of Internet addiction in Greek adolescent students over a two-year period: The impact of parental bonding. European Child \& Adolescent Psychiatry, 21(4), 211-219. doi:10.1007/ s00787-012-0254-0

Steinbeis, N., Haushofer, J., Fehr, E., \& Singer, T. (2016). Development of behavioral control and associated vmPFC-DLPFC connectivity explains children's increased resistance to temptation in intertemporal choice. Cerebral Cortex, 26(1), 32-42. doi:10.1093/cercor/bhu167

Swanson, J. M., Kraemer, H. C., Hinshaw, S. P., Arnold, L. E., Conners, C. K., Abikoff, H. B., Davies, M., Elliott, G. R., Greenhill, L. L., Hechtman, L., Hoza, B., Jensen, P. S., March, J. S., Newcorn, J. H., Owens, E. B., Pelham, W. E., Schiller, E., Severe, J. B., Simpson, S., Vitiello, B., Wells, K., Wigal, T., \& 
$\mathrm{Wu}, \mathrm{M}$. (2001). Clinical relevance of the primary findings of the MTA: Success rates based on severity of ADHD and ODD symptoms at the end of treatment. Journal of the American Academy of Child and Adolescent Psychiatry, 40(2), 168-179. doi:10.1097/00004583-200102000-00011

Van den Bulck, J. (2000). Is television bad for your health? Behavior and body image of the adolescent 'couch potato'. Journal of Youth and Adolescence, 29(3), 273-288. doi:10.1023/A:1005102523848

Yen, C. F., Ko, C. H., Yen, J. Y., Chang, Y. P., \& Cheng, C. P. (2009). Multi-dimensional discriminative factors for Internet addiction among adolescents regarding gender and age. Psychiatry and Clinical Neurosciences, 63(3), 357-364. doi:10.1111/j.1440-1819.2009.01969.x

Yen, J. Y., Ko, C. H., Yen, C. F., Wu, H. Y., \& Yang, M. J. (2007). The comorbid psychiatric symptoms of Internet addiction: Attention deficit and hyperactivity disorder (ADHD), depression, social phobia, and hostility. Journal of Adolescent Health, 41(1), 93-98. doi:10.1016/j. jadohealth.2007.02.002

Yen, J. Y., Yen, C. F., Chen, C. C., Chen, S. H., \& Ko, C. H. (2007). Family factors of internet addiction and substance use experience in Taiwanese adolescents. CyberPsychology \& Behavior, 10(3), 323-329. doi:10.1089/cpb.2006.9948

Yoo, H. J., Cho, S. C., Ha, J., Yune, S. K., Kim, S. J., Hwang, J., Chung, A., Sung, Y. H., \& Lyoo, I. K. (2004). Attention deficit hyperactivity symptoms and Internet addiction. Psychiatry and Clinical Neurosciences, 58(5), 487-494. doi:10.1111/j.1440-1819.2004.01290.x 